\title{
Incidence and antimicrobial susceptibility of Neisseria gonorrhoeae isolates from patients attending the national Neisseria gonorrhoeae reference laboratory of Hungary
}

Alexandra Brunner ${ }^{1 \dagger}$, Eva Nemes-Nikodem ${ }^{1+}$, Noemi Mihalik', Marta Marschalko ${ }^{1}$, Sarolta Karpati ${ }^{1}$ and Eszter Ostorhazi ${ }^{1,2^{*}}$

\begin{abstract}
Background: The Hungarian national guidelines for the treatment of gonorrhoea were published in 2002 but are now widely considered to be outdated. Improved knowledge is needed with respect to the epidemiology and antimicrobial susceptibility of Neisseria gonorrhoeae strains currently circulating in Hungary not least for the construction of updated local recommendations for treating gonorrhoea. European guidelines are based mostly on western European data raising concerns locally that recommended treatments might not be optimised for the situation in Hungary. We report our recent study on the distribution of antibiotic resistance in various Hungarian (East European) Neisseria gonorrhoeae strains isolated from patients with gonorrhoea over the past four years.

Methods: Between January 2010 and December 2013, isolates of N. gonorrhoeae were obtained from sexually active individuals during medical examination at the STD Center of Semmelweis University in Budapest. The minimal inhibitory concentrations (MIC) of azithromycin, cefixime, ceftriaxone, ciprofloxacin, penicillin, tetracycline and spectinomycin were determined to establish the antimicrobial susceptibility of the strains currently circulating in patients that attend our clinic.
\end{abstract}

Results: Among the 9097 patients tested, 582 had an N. gonorrhoeae infection as detected by culture. The isolates were all sensitive to ceftriaxone and spectinomycin and 581/582 strains were sensitive to cefixime. In contrast, the number of detected strains with elevated azithromycin MIC did increase over the time period examined to approximately $16 \%$ in 2013. There was a high percentage of detected resistance to penicillin (77\%), tetracycline (86\%), and ciprofloxacin (66\%) in the isolates examined in this study.

Conclusion: Current European guidelines recommend $2 \mathrm{~g}$ azithromycin in addition to $500 \mathrm{mg}$ ceftriaxone as first choice therapy for gonorrhoea. For the purposes of revising the Hungarian national treatment guidelines, apparent increasing resistance to azithromycin during the last four years should be accounted for. It is also clear that penicillin, tetracycline and ciprofloxacin are inappropriate treatment measures at least locally. We also recommend that culture should form part of the diagnostic pathway of gonorrhoea, followed by antibiotic susceptibility testing with MIC determination. This will provide valuable continued monitoring of antibiotic resistance development in strains of Neisseria gonorrhoeae circulating in Hungary.

Keywords: Neisseria gonorrhoeae, Antimicrobial resistance, Incidence, MIC, Hungary

\footnotetext{
* Correspondence: droeszter@gmail.com

${ }^{\dagger}$ Equal contributors

'Department of Dermatology, Venerology and Dermatooncology,

Semmelweis University, Mária u. 41, 1085 Budapest, Hungary

${ }^{2}$ Institute of Medical Microbiology, Semmelweis University, Nagyvárad tér 4,

1089 Budapest, Hungary
}

\section{Biomed Central}

(c) 2014 Brunner et al.; licensee BioMed Central Ltd. This is an Open Access article distributed under the terms of the Creative Commons Attribution License (http://creativecommons.org/licenses/by/4.0), which permits unrestricted use, distribution, and reproduction in any medium, provided the original work is properly credited. The Creative Commons Public Domain Dedication waiver (http://creativecommons.org/publicdomain/zero/1.0/) applies to the data made available in this article, unless otherwise stated. 


\section{Background}

$N$. gonorrhoeae infections represent 106 million of the estimated 498 million new cases of curable sexually transmitted infection (STI) that occur globally every year [1]. In 2008, the World Health Organization (WHO) estimated 3.4 million cases among adults in the European Union (EU) [1]. Gonorrhoea remains the second most commonly reported bacterial STI after chlamydia infection [2]. Gonococcal infection, depending on the anatomic site of exposure can cause acute urethritis, cervicitis, proctitis or pharyngitis. However, most cervical, pharyngeal and rectal infections are asymptomatic. Untreated or inadequately treated gonorrhoea can cause serious reproductive complications in women. This includes pelvic inflammatory disease, infertility and ectopic pregnancy.

Hungary has a population of 10 million people and is served by 135 sexual health care units that are financed by the government. There are also more than 300 private venerologists available to help patients with STDs. In Hungary, gonorrhoeal infection cases must be notified to the National Epidemiological Center regardless of whether they were detected with nucleic acid amplification tests (NAATs), culture or only microscopically. The notification contains the age, gender and sexual orientation of the patient, the anatomical sites of the infection and the region of the country where the infection was detected.

The Hungarian national guidelines on the diagnosis and treatment of gonorrhoea [3] were published in 2002. These guidelines recommend 1x $250 \mathrm{mg}$ ceftriaxone i.m. or $400 \mathrm{mg}$ ofloxacin per os as first choice treatment, or $400 \mathrm{mg}$ cefixime per os or $500 \mathrm{mg}$ ciprofloxacin per os can be administered in cases of uncomplicated gonorrhoeal urethritis or cervicitis. The guidelines also allow diagnosis of gonorrhoeal urethritis in symptomatic men based only on a Gram stain of the male urethral specimen and a demonstration of the presence of polymorphonuclear leukocytes with intracellular Gram-negative diplococci. While this test is fast to administer and typically very reliable, it limits any opportunities to monitor the development of antibiotic resistance in $N$. gonorrhoeae a phenomenon that is causing widespread concern globally.

In 2013, N. gonorrhoeae infections were notified in 1563 cases in Hungary [4]. However no reliable data with respect to antimicrobial resistance (AMR) exists because most diagnoses were based on microscopic analysis or NAATs and did not include any culturing (which is required for determining AMR). The National Reference Laboratory of $N$. gonorrhoeae, a part of the STD Center of Semmelweis University, receives patients and samples from all over the country. At our centre, diagnosis of gonorrhoea is made by culture, meaning that AMR development within Hungary can be monitored retrospectively.
The aims of this study were therefore to investigate $N$. gonorhoeae infection rates according to gender, age and anatomic location of the symptoms, and to determine phenotypic AMR of the isolates obtained from patients with gonorrhoea who visited our clinic over the previous four years. A specific objective of the study was to understand the appropriateness of current Hungarian treatment recommendations especially with respect to suspected local development of AMR in circulating $N$. gonorrhoreae strains.

\section{Methods}

All studies were carried out at the STD Center of Department of Dermatology, Venereology and Dermatooncology of Semmelweis University, Budapest, Hungary. Over a four-year period (January 2010 to December 2013), N. gonorrhoeae isolates were obtained from patients attending medical examinations for a suspected STI. During medical examination by a physician, patient data was also collected with respect to their age, sex, sexual orientation and anatomic site of infection. The isolates were cultured from consecutively symptomatic gonorrhoea patients and from their asymptomatic contacts. All isolates were collected as part of standard patient care and patients gave and signed informed consent. Patient data was analysed according to law 1997/CLIV 26\$ taking into account maximum privacy rights and anonimity of patients [5]. Ethical approval signed by the Semmelweis University Regional and Institutional Committee of Science and Research Ethics was not required for the study because all used methods were not more than normally needed for diagnosis and treatment.

For the identification of $N$. gonorrhoeae, cervical, anal, urethral and pharyngeal swabs were taken and cultured on preheated VCA3 agar (Biomérieux, Budapest, Hungary) and on non-selective PVX chocolate agar (Biomérieux, Budapest, Hungary). Cultures were incubated for 24-48 hours at a temperature of $36.5^{\circ} \mathrm{C}$ with $5 \%$ carbon dioxide, and their identification and penicillinase production was confirmed using NH-API strip tests (Biomérieux, Budapest, Hungary).

Minimum inhibitory concentrations (MIC; $\mathrm{mg} / \mathrm{L}$ ) of cefixime, ceftriaxone, penicillin, tetracycline, azithromycin, spectinomycin and ciprofloxacin were determined on PVX chocolate agar (Biomérieux, Budapest, Hungary) using MIC strip tests (Liofilchem ${ }^{\bullet}$ s.r.l., Roseto degli Abruzzi, Italy), according to the manufacturer's instructions, and by using a direct colony suspension equivalent to a $0.5 \mathrm{McFarland}$ standard. Testing conditions also included incubation at $36.5^{\circ} \mathrm{C}$ and $5 \%$ carbon dioxide for 24 hours. All results were interpreted by using breakpoints for susceptibility and resistance according to the European Committee on Antimicrobial Susceptibility Testing (EUCAST) (Table 1) [6]. To ensure the quality of the culture media 
Table $1 \mathrm{~N}$. gonorrhoeae MIC breakpoints for susceptibility and resistance according to the European Committee on Antimicrobial Susceptibility Testing (EUCAST)

\begin{tabular}{lll}
\hline & Sensitive $(\mathbf{m g} / \mathbf{L})$ & Resistant $(\mathbf{m g} / \mathbf{L})$ \\
\hline penicillin & $\leq 0,06$ & $>1$ \\
cefixime & $\leq 0,12$ & $>0,12$ \\
ceftriaxone & $\leq 0,12$ & $>0,12$ \\
ciprofloxacin & $\leq 0,03$ & $>0,06$ \\
azithromycin & $\leq 0,25$ & $>0,5$ \\
tetracycline & $\leq 0,5$ & $>1$ \\
spectinomycin & $\leq 64$ & $>64$
\end{tabular}

Source: [http://www.who.int/drugresistance/

Antimicrobial_resistance_in_Neisseria_gonorrhoeae.pdf].

and susceptibility tests, $N$. gonorrhoeae ATCC 49226 was used as a control strain. Isolates were classified as having a presumed high level of resistance to tetracycline (TRNG) if $\mathrm{MIC}$ was $\geq 16 \mathrm{mg} / \mathrm{L}$, and as having a presumed plasmidmediated resistance to penicillin (PPNG) if they were $\beta$ lactamase positive [7].

\section{Results}

We examined the prevalence of $N$. gonorrhoeae infection in 9097 sexually active patients attending the Hungarian National STD Center between January 2010 and December 2013. A total of 26383 swab samples were collected during the study period. These samples, taken from urethra, cervix, anus, pharynx or conjunctiva were examined by culture. Over the period of the four years of the study the number of patients who visited the STD Center increased by $10.0 \%$ (Table 2). Depending on the symptoms observed, gender and anamnesis, one to five swab samples were collected for culturing. There was a concurrent increase in the number of samples collected of $8.7 \%$ over the study period (Table 2). The ratio of $N$. gonorrhoeae positive samples to total samples collected increased from $1.9 \%$ at the beginning of 2010 to $3.2 \%$ by the end of 2013. The ratio of positive patients to total patients examined increased from $5.2 \%$ in 2010 to $7.8 \%$ by the end of 2013 (Table 2). Out of the total number of samples collected, $N$. gonorrhoeae infection was confirmed in 673 samples and 582 patients (of both sexes). This included 16 samples taken from five patients who had returned to the clinic with new infections.
In terms of total population studied the majority of patients attending the clinic were male in all years of the study. Specifically, the male to female ratio of patients attending the STD Center were 62/38\%, 58/42\%, 57/43\% and 61/39\% in 2010, 2011, 2012 and 2013 respectively. On average over the study period 86\% (498/582) of cases examined that were subsequently determined to be positive for $N$. gonorrhoeae were men, with the balance of cases $(14 \%(84 / 582))$ female. $86 \%(96 / 112), 85.5 \%$ (106/144), 84\% (133/159) and 87\% (163/187) were male patients in 2010, 2011, 2012 and 2013, respectively. Ages ranged from 14 to 76 years with an average of 31.7 years for male and 26.7 years for female patients (Figure 1). Among the infected male patients, 19\% (95/ 498) declared that they were men who have sex with men (MSM), while $81 \%(403 / 495)$ declared they were heterosexual. The dominant anatomical site of gonococcal infections was urethra in male $(80 \%, 437 / 548)$ and cervix in female patients $(62 \%, 77 / 125)$. Pharyngeal and anal infections were identified both separately and in parallel with the dominant urethral infection in men or cervical infection in female patients. Only one extragenital $N$. gonorrhoeae infection causing conjunctivitis was detected in a male patient, who had gonorrhoeal urethritis and pharyngitis at the same time (Table 3).

We performed antimicrobial susceptibility tests on all 673 isolates. We found that isolates from different anatomical sites of the same patients did not differ in terms of MICs for the antibiotics we tested. Based on this observation, calculated percentages are based on data from single isolates (as in one strain) per patient (582 samples in total). The antimicrobial susceptibility rates of N. gonorrhoeae to azithromycin, cefixime, ceftriaxone, ciprofloxacin, penicillin, tetracycline and spectinomycin are given in Table 4. Almost all isolates were susceptible to ceftriaxone, cefixime ( $\mathrm{MIC} \leq 0.12 \mathrm{mg} / \mathrm{L}$ ) and spectinomycin $(\mathrm{MIC} \leq 64 \mathrm{mg} / \mathrm{L})$. However there were small increases in the MIC averages for ceftriaxone, cefixime and spectinomycin between the beginning of 2010 and the end of 2013 . These were $0.002 \mathrm{mg} / \mathrm{L}$ to $0.019 \mathrm{mg} / \mathrm{L}$ for ceftriaxone, $0.016 \mathrm{mg} / \mathrm{L}$ to $0.047 \mathrm{mg} / \mathrm{L}$ for cefixime and $2 \mathrm{mg} / \mathrm{L}$ to $8 \mathrm{mg} / \mathrm{L}$ for spectinomycin. In the last case, we did identify two isolates with an MIC of $48 \mathrm{mg} / \mathrm{L}$. In 2013 we also observed for the first time (in our laboratory) three strains that exceeded breakpoints: two strains with a

Table 2 Number of patients, samples for culture, N. gonorrhoeae positive samples and $\mathbf{N}$. gonorrhoeae infected patients at the STD Centre of Semmelweis University, 2010-2013

\begin{tabular}{llllll}
\hline & $\mathbf{2 0 1 0}$ & $\mathbf{2 0 1 1}$ & $\mathbf{2 0 1 2}$ & $\mathbf{2 0 1 3}$ & Total \\
\hline Number of patients & 2167 & 2229 & 2317 & 2384 & 9097 \\
Number of tested samples & 6397 & 6350 & 6682 & 6954 & 26383 \\
N. gonorrhoeae positive samples (Number/\%) & $129 / 1.9 \%$ & $144 / 2.2 \%$ & $178 / 2.7 \%$ & $222 / 3.2 \%$ & $673 / 2.5 \%$ \\
N. gonorrhoeae infected patients (Number/\%) & $112 / 5.2 \%$ & $124 / 5.6 \%$ & $159 / 6.9 \%$ & $187 / 7.8 \%$ & $582 / 6.4 \%$ \\
\hline
\end{tabular}




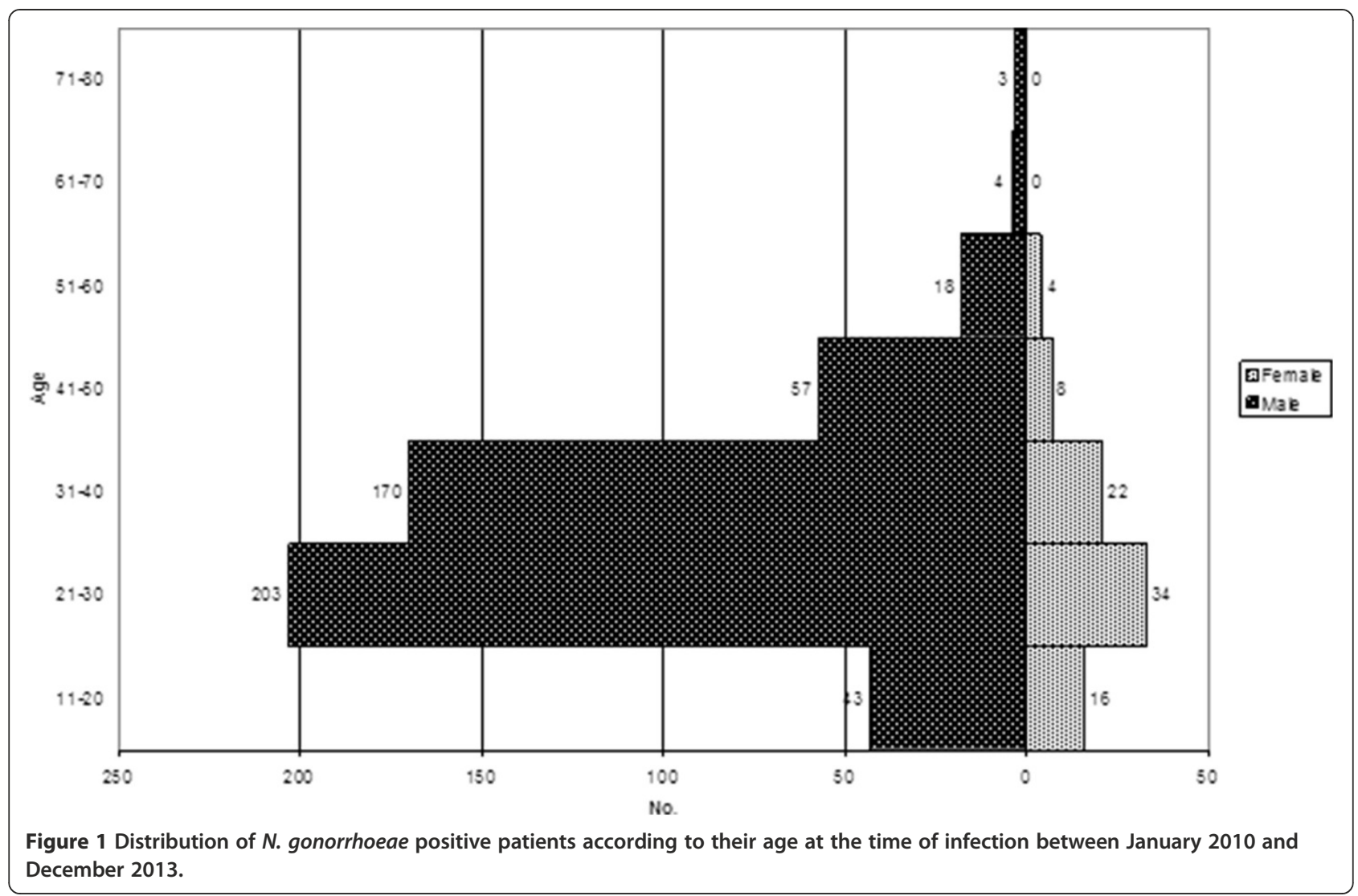

cefixime MIC of $0.125 \mathrm{mg} / \mathrm{L}$ and one strain with a cefixime MIC of $0.19 \mathrm{mg} / \mathrm{L}$. In strict accordance with EUCAST recommendations this means $0.51 \%$ of the strains had a cefixime MIC just above the resistant breakpoint. Resistance to azithromycin (MIC $>0.5 \mathrm{mg} / \mathrm{L}$ ) increased from 0 to $15.86 \%$ of strains tested during the four years of the study.

The prevalence of ciprofloxacin and tetracycline resistance varied year to year but was consistently high for both antibiotics (66\% and 86\%, respectively) (see Table 4). The prevalence of penicillin resistance appeared to slowly increase from 75 to $79 \%$ in the four years of the study. PPNG was detected in $16.2 \%$ of the isolates and

Table 3 Distribution of specimens cultured for $\mathbf{N}$. gonorrhoeae strains between January 2010 and December 2013

\begin{tabular}{lllll}
\hline Samples & Men & $\%$ & Women & $\%$ \\
\hline Cervix & 0 & 0 & 77 & 61.6 \\
Pharynx & 22 & 4.0 & 11 & 8.8 \\
Anus & 88 & 16.1 & 10 & 8.0 \\
Urethra & 437 & 79.7 & 27 & 21.6 \\
Conjunctiva & 1 & 0.2 & 0 & 0 \\
Total & 548 & 100 & 125 & 100 \\
\hline
\end{tabular}

TRNG in $23 \%$, whereas $14.8 \%$ of the isolates presented both phenotypes (PPNG/TRNG).

\section{Discussion}

In Hungary, as is the case in many other countries, the control of gonococcal infections mostly relies on an effective single-dose antibiotic therapy given at the first clinical presentation of the patient. Prior knowledge of the antimicrobial susceptibility pattern of the particular strain infecting the patient is routinely not established however. With increasing evidence of antimicrobial resistance in gonococcal infections there is therefore a real risk of treatment failure and development of further resistance

Table 4 Distribution of antibiotic resistant $\mathbf{N}$. gonorrhoeae strains (\%) in Hungary

\begin{tabular}{lllll}
\hline Resistance to antibiotics/year & $\mathbf{2 0 1 0}$ & $\mathbf{2 0 1 1}$ & $\mathbf{2 0 1 2}$ & $\mathbf{2 0 1 3}$ \\
\hline Azithromycin & 0 & 0.8 & 6.9 & 15.9 \\
Cefixime & 0 & 0 & 0 & 0.2 \\
Ceftriaxone & 0 & 0 & 0 & 0 \\
Ciprofloxacin & 70.5 & 61.7 & 64.6 & 67.2 \\
Penicillin & 75.4 & 76.2 & 77.3 & 79.5 \\
Spectinomycin & 0 & 0 & 0 & 0 \\
Tetracycline & 88.1 & 87.5 & 82.9 & 85.5 \\
\hline
\end{tabular}


to antibiotics. Current Hungarian guidelines for the diagnosis and treatment of gonorrhoea date from 2002 and are based on bygone national and international data of gonococcal resistance. Our study therefore sought to understand ongoing resistance trends with respect to gonorrhoea in Hungary, and to ultimately contribute to the preparation of new guidelines to ensure the success of any therapies targeting gonorrhoea. Our data, based on sampling over the previous four years highlight that there appears to be continued antimicrobial resistance in circulating strains of $N$. gonorrhoeae strains to a variety of common antibiotics (including high rates of resistance to ciprofloxacin, which is one of the antibiotics recommended in the national Hungarian guidelines) and that there may be developing resistance to others (including azithromycin and penicillin and possibly even cefixime) in this part of eastern Europe.

Over the last 70-80 years treatment options have diminished due to the emergence and spread of resistance to all drugs recommended for treatment of gonorrhoea. Plasmidmediated resistance mechanisms have been described for penicillins (PPNG) and tetracyclines (TRNG), but not for sulphonamides, macrolides, spectinomycin, aminoglycosides, quinolones and cephalosporines. In these cases only chromosomal mutations have been described as the reason for resistance [8]. Since $N$. gonorrhoeae is naturally competent for the uptake and recombination of external DNA during its entire life cycle, the transfer of chromosomally encoded resistance genes is both rapid and extensive in comparison to uptake of plasmidmediated resistance genes [9]. Resistance may initially emerge in the commensal Neisseria spp. inhabiting the human body as these are exposed more frequently to antimicrobials than the transiently acquired gonococci. The commensal Neisseria spp. can act as a reservoir of resistance genes that can be transferred to gonococci through transformation. In our study $N$. gonorrhoeae was detected in pharyngeal swab samples of symptomatic or asymptomatic infected patients in 4 and $8 \%$ of male and female patients, respectively. This may be significant as the pharynx may be an ideal anatomic site to provide the opportunity for chromosomally encoded resistance development. Pharyngeal gonorrhoea is mostly asymptomatic meaning that commensal Neisseria spp. and $N$. gonorrhoeae can co-exist for extended time periods in the pharynx and share genetic material [10-12]. This is likely to include the transfer of antibiotic resistance genes and therefore the development of antibiotic resistance in $N$. gonorrhoeae. As humans appear to be the obligate host of $N$. gonorrhoeae it would appear that control of resistance lies in appropriate treatment regimes and that includes correct usage of antibiotics. The emergence and spread of antimicrobial resistance in $N$. gonorrhoeae all over the world requires the control of incidence of gonorrhoea through education and appropriate sexual practices and control of antimicrobial resistance through appropriate antibiotic usage. This is particularly the case in Hungary where both incidence of gonorrhoea and antibiotic resistance appear to be increasing in recent years.

According to data from the National Epidemiological Center the incidence of $N$. gonorrhoeae infection appears to be increasing in Hungary - the number of the reported (notified) cases was 1158 in 2010, 1369 in 2011, 1491 in 2012 and 1563 in 2013 [4]. In the report of the National Epidemiological Center, $75-82 \%$ of the infections were detected in male patients and the dominant site of infection was urethra in male (81\%), and cervix in female $(62 \%)$ (in this time period in Hungary). About $10 \%$ of the notifiable infections were diagnosed at the STD Center of Semmelweis University during this period, and the distribution according to gender, age and location of the symptoms was the same as the national results.

To our knowledge the only available data relating to the distribution of resistance against different antibiotics of the Hungarian $N$. gonorrhoeae strains exist in the surveillance reports of EURO-GASP (European Gonococcal Antimicrobial Surveillance Programme) [13,14]. In these projects 14 and $13 N$. gonorrhoeae strains were collected from Hungary in 2010 and 2011. These data were collected from a sentinel laboratory based on the report of a selected group of physicians $[13,14]$. In these reports there were no Hungarian $N$. gonorrhoeae strains with PPNG property. All these strains were susceptible to azithromycin, and $79 \%$ or $61.5 \%$ were resistant to ciprofloxacin in 2010 and 2011, respectively. These data contained no occurrence of cefixime resistant strains in 2010, but $1 \%$ of the isolates had decreased susceptibility to cefixime in 2011.

In our work we processed $582 N$. gonorrhoeae strains, which corresponds to approximately $10 \%$ of the total number of notified infections in Hungary during the period between the beginning of 2010 and the end of 2013. This provides a more representative assessment of antimicrobial resistance to $N$. gonorrhoeae than any other previous survey carried out in Hungary.

Among our $582 \mathrm{~N}$. gonorrhoeae isolates generally no resistance occurred against ceftriaxone, cefixime and spectinomycin. These results were interpreted using breakpoints for susceptibility and resistance according to the EUCAST [6]. All the measured MICs were not higher than their respective resistance breakpoints, with the exception of three strains isolated in 2013, which showed slightly raised resistance towards cefixime. Year on year there was a small increase in MIC averages for ceftriaxone, cefixime and spectinomycin. These averages did not exceed resistance breakpoints with the exception of the three cases mentioned above. We also found a small increase in the number of penicillin resistant 
strains during the study period. The rate of PPNG strains was stable at around $16 \%$, which suggests different chromosomal mutations may be reasonably assumed for this type of resistance development. The acquisition of a mosaic penA gene encoding a remodelled penicillin binding protein (PBP2) and overproduction of an efflux pump in $N$. gonorrhoeae appears to be responsible for reduced susceptibility to cephalosporins [15]. Since the first ceftriaxone-resistant isolates were identified in Japan (2009), France (2010), and Spain (2011) [16-18], a real threat now exists that extensively resistant strains of $N$. gonorrhoeae may emerge and spread worldwide. Enhanced surveillance for resistance against other anti-gonococcal agents is therefore warranted.

According to the EUCAST interpretations all of the strains were susceptible to spectinomycin with a MIC lower than $64 \mathrm{mg} / \mathrm{L}$. The average spectinomycin MIC increased during the study period and we did identify two isolates with clearly elevated $(48 \mathrm{mg} / \mathrm{L}$ ) MICs, suggesting that only intermediate sensitivity can be assured (according to the recommendation of Clinical and Laboratory Standards Institute (CLSI) [19]). Verified resistance to spectinomycin is exceedingly rare worldwide with only five spectinomycin-resistant isolates (all between 1988 and 1990) identified in the US Gonococcal Isolate Surveillance Project [20] using the CLSI recommendation. In comparison no spectinomycin-resistant isolates have been identified in the EURO-GASP in 2010-2011 [13,14].

The very common occurrence (82-88\% in Hungary over the past four years in our study) of tetracycline resistant strains is not unique in comparison to other countries. Despite some exceptions (in the USA, tetracycline resistance rates are only 22.5\% [21] while rates in South America and the Caribbean decreased from a level of $61.1 \%$ of isolates tested in 2001 to $21.8 \%$ in 2010 [22]), high prevalence of tetracycline resistance has been detected in some countries in South East Asia. Bhutan and Indonesia reported a resistance rate of more than 95\% between 2009 and 2012 [23], and a rate of 92.8\% tetracycline resistance was noted in North Africa in 2009 [24]. This high percentage of detected resistance to tetracycline indicates that this antibiotic is certainly not appropriate for gonorrhoea treatment in Hungary and probably elsewhere.

Furthermore, the effectiveness of the quinolone antibiotics appears to be equally limited. For example, the prevalence of ciprofloxacin resistant strains that we detected in this study was between $61-70 \%$ over the previous four years. In comparison, prevalence of ciprofloxacin resistance in the USA was $13.5 \%$ [21], while in Latin America and the Caribbean ciprofloxacin rates increased from $1.6 \%$ of isolates tested in 1997 to $42.1 \%$ in 2010 [21]. Rates of ciprofloxacin resistance have decreased continuously since 2009 in the participant countries of EURO-GASP, but still remained as high as $52.7 \%$ and $48.7 \%$ in 2010 and 2011 , respectively [13,14]. The usage of ciprofloxacin, which was previously recommended in gonorrhoea treatment in Hungary, is no longer suitable according to the rates of resistance we observed in recent years.

Resistance to azithromycin (MIC $>0.5 \mathrm{mg} / \mathrm{L}$ ) increased from 0 to $15.86 \%$ during the four years of our study. The Centers for Disease Control and Prevention [25] and the International Union against Sexually Transmitted Infections (IUSTI) [26] published global and European guidelines for diagnosis and/or treatment of $N$. gonorrhoeae to combat and mitigate the spread of multidrug-resistant gonorrhoea. Their new treatment guidelines revised the recommended treatment to be $250 \mathrm{mg}$ or $500 \mathrm{mg}$ ceftriaxone im combined with $1 \mathrm{~g}$ or $2 \mathrm{~g}$ azithromycin per os, respectively. However, based on past and current data reported in this study, $N$. gonorrhoeae may continue to emerge with azithromycin resistance in our country, especially as increased usage of this antibiotic is expected. The World Health Organization has suggested that an antimicrobial should not be used when $>5 \%$ of strains demonstrate resistance [27]. If our data can be verified it would appear that this cut-off has already been passed in Hungary. In addition to complying with the new recommendations it is necessary to also adequately run antimicrobial surveillance programmes. It would be advisable to now include surveillance for ceftriaxone and azithromycin resistance, not least to control the emergence of extremely drug resistant strains.

\section{Conclusion}

Our study contributes large amounts of data on the current antimicrobial susceptibility rates of circulating $N$. gonorrhoeae strains in Hungary in the period between the beginning of 2010 and up to the end of 2013. It is clear that there are considerable levels of antimicrobial resistance in circulating strains and in some cases resistance may be emerging. Of concern is that such resistance may be emerging towards antibiotics that are currently recommended as first line treatments for gonorrhoea in Hungary. Current diagnosis approaches typically only utilise Gram staining techniques, which while regarded as highly accurate, do not allow antibiotic resistance to be monitored routinely. Based on our observations we are now of the opinion that culture and susceptibility testing are indispensable in the currently developing situation of multidrug resistance among the $N$. gonorrhoeae strains. It is somewhat reassuring that during the previous four years, resistance has not been identified towards the recommended treatment of ceftriaxone in Hungary. However, in Europe extensively drug resistant $N$. gonorrhoeae strains have emerged and we believe it is only a matter of time before this occurs in Hungary if appropriate control 
measures and surveillance are not implemented soon. This emergence of resistance should prompt revision of our national diagnosis and treatment guidelines. The recommendations of IUSTI and other international organisations involved in developing advice and treatment approaches for gonorrhoea should be considered. However in Hungary the incidence of azithromycin resistance appears to have increased over recent years and this should be taken into account in developing any new guidelines.

\begin{abstract}
Abbreviations
AMR: Antimicrobial resistance; CLSI: Clinical and laboratory standards institute; EUCAST: European committee on antimicrobial susceptibility testing; EURO-GASP: European gonococcal antimicrobial surveillance programme; IUSTI: International union against sexually transmitted infections; MIC: Minimal inhibitory concentrations; MSM: Men who have sex with men; PBP: Penicillin binding protein; PPNG: Penicillinase producing Neisseria gonorrhoeae; TRNG: Tetracycline resistant Neisseria gonorrhoeae.
\end{abstract}

\section{Competing interests}

The authors declare that they have no competing interests.

\section{Authors' contributions}

$B A, N N E$ collected the retrospective data. OE wrote the manuscript. BA, NNE, MN and $\mathrm{OE}$ conducted the review of the literature relevant to the paper. MN, MM and SK examined and treated the patients. BA, NNE and OE performed identification and susceptibility testing of the strains. All authors contributed suggestions to the manuscript. All authors read and approved the final manuscript.

\section{Acknowledgements}

We would like to acknowledge the technical assistance of Ildikó Bencze Győriné and Elvira Vörös. We would also like to thank Max Bingham, PhD (freelance editor, Rotterdam, The Netherlands) for technical writing and editorial assistance prior to submission.

Received: 12 March 2014 Accepted: 30 July 2014

Published: 6 August 2014

\section{References}

1. World Health Organization (WHO), Department of Reproductive Health and Research: Global action Plan to Control the Spread and Impact of Antimicrobial Resistance in Neisseria Gonorrhoeae. In Geneva: WHO 2012:1-36 [http://www.who.int/reproductivehealth/publications/rtis/ 9789241503501/en/]. ISBN 9789241503501.

2. European Centre for Disease Prevention and Control (ECDC): Response Plan to Control and Manage the Threat of Multi-Drug Resistant Gonorrhoea in Europe. In Stockholm: ECDC; 2012:1-23. doi:10.2900/60053 [http://www. ecdc.europa.eu/en/publications/publications/1206-ecdc-mdr-gonorrhoearesponse-plan.pdf]. ISBN 9789291933754.

3. Bör- és Nemi Betegségek Szakmai Kollégiuma/ Skin and Venereal Diseases Professional College: Módszertani ajánlás a szexuális úton terjedő infekciók kivizsgálására és kezelésére/ Methodological letter of detection of sexually transmitted infections and treatment. Egészségügyi Közlöny/Health Bulletin 2002, 52:1509-1518 [http://www.otszonline.hu/cikk/modszertani_ajanlas_ a_szexualis_uton_terjedo_infekciok_kivizsgalasara_es_kezelesere]

4. Országos Epidemiológiai Központ (OEK)/ National Epidemiological Center: Szexuális úton terjedő betegségek Magyarországon/Sexually transmitted diseases in Hungary 2013. IV. Epinfo 2014, 5:45-50 [www.oek.hu/oekfile.pl? fid $=3813]$

5. Magyar Országgyülés/ Parlament of Hungary: Hatályos jogszabályok gyüjteménye /Collection of existing legislation. [http://net.jogtar.hu/jr/ gen/hjegy_doc.cgi?docid=99700154.TV]

6. The European Committee on Antimicrobial Susceptibility Testing: Breakpoint Tables for Interpretation of MICs and Zone Diameters. 2014 [http://www.eucast.org/fileadmin/src/media/PDFs/EUCAST_files/ Breakpoint_tables/Breakpoint_table_v_4.0.pdf]

7. Tapsall JW: Antibiotic resistance in Neisseria gonorrhoeae. Clin Infect Dis 2005, 41(Supplement 4):S263-S268. doi:10.1086/430787.
8. Lewis DA, Lukehart SA: Antimicrobial resistance in Neisseria gonorrhoeae and Treponema pallidum: evolution, therapeutic challenges and the need to strengthen global surveillance. Sex Transm Infect 2011, 87:ii39-ii43. doi:10.1136/sti.2010.047712.

9. Unemo M, Shafer WM: Antibiotic resistance in Neisseria gonorrhoeae: origin, evolution, and lessons learned for the future. Ann NY Acad Sci 2011, 1230:E19-E28. doi:10.1111/j.1749-6632.2011.06215.x.

10. Unemo M, Nicholas RA: Emergence of multidrug-resistant, extensively drug-resistant and untreatable gonorrhea. Future Microbiol 2012, 7:1401-1422. doi:10.2217/fmb.12.117.

11. Furuya R, Onoye Y, Kanayama A, Saika T, lyoda T, Tatewaki M, Matsuzaki K, Kobayashi I, Tanaka M: Antimicrobial resistance in clinical isolates of Neisseria subflava from the oral cavities of a Japanese population. $J$ Infect Chemother 2007, 13:302-304. doi:10.1007/s10156-007-0541-8.

12. Saika T, Nishiyama T, Kanayama A, Kobayashi I, Nakayama H, Tanaka M, Naito S: Comparison of Neisseria gonorrhoeae isolates from the genital tract and pharynx of two gonorrhea patients. J Infect Chemother 2001, 7:175-179. doi:10.1007/s101560100031.

13. European Centre for Disease Prevention and Control: Gonococcal Antimicrobial Susceptibility Surveillance in Europe - 2010. 2012. [http://ecdc. europa.eu/en/publications/Publications/1206-Gonococcal-AMR.pdf] (Accessed 18 Apr 2013).

14. European Centre for Disease Prevention and Control: Gonococcal Antimicrobial Susceptibility Surveillance in Europe 2011. 2013. [http://ecdc. europa.eu/en/publications/Publications/gonococcal-antimicrobialsusceptibility-surveillance-27-mar 2013.pdf] (accessed 18 Apr 2013)

15. Ito M, Deguchi T, Mizutani KS, Yasuda M, Yokoi S, Ito S, Takahashi Y, Ishihara S, Kawamura Y, Ezaki T: Emergence and spread of Neisseria gonorrhoeae clinical isolates harboring mosaic-like structure of penicillin-binding protein 2 in Central Japan. Antimicrob Agents Chemother 2005, 49:137-143. doi:10.1128/AAC.49.1.137-143.2005.

16. Ohnishi M, Golparian D, Shimuta K, Saika T, Hoshina S, Iwasaku K, Nakayama S, Kitawaki J, Unemo M: Is Neisseria gonorrhoeae initiating a future era of untreatable gonorrhea? Detailed characterization of the first strain with high-level resistance to ceftriaxone. Antimicrob Agents Chemother 2011, 55:3538-3545. doi:10.1128/AAC.00325-11.

17. Unemo M, Golparian D, Nicholas R, Ohnishi M, Gallay A, Sednaoui P: High-level cefixime- and ceftriaxone-resistant Neisseria gonorrhoeae in France: novel penA mosaic allele in a successful international clone causes treatment failure. Antimicrob Agents Chemother 2012, 56:1273-1280. doi:10.1128/AAC.05760-11.

18. Cámara J, Serra J, Ayats J, Bastida T, Carnicer-Pont D, Andreu A, Ardanuy C: Molecular characterization of two high-level ceftriaxone-resistant Neisseria gonorrhoeae isolates detected in Catalonia, Spain. J Antimicrob Chemother 2012, 67:1858-1860. doi:10.1093/jac/dks162.

19. Clinical and Laboratory Standards Institute: Performance Standards for Antimicrobial Susceptibility Testing; Twenty-First Informational Supplement. CLSI Document M100-S21 (ISBN 1-56238-742-1). 940 West Valley Road, Suite 1400, Wayne, Pennsylvania 19087 USA: Clinical and Laboratory Standards Institute; 2011.

20. Gorwitz RJ, Nakashima AK, Moran JS, Knapp JS: Sentinel Surveillance for Antimicrobial Resistance in Neisseria gonorrhoeae - United States, 19881991: the gonococcal isolate surveillance project study group. MMWR CDC Surveill Summ 1993, 42:29-39 [http://www.cdc.gov/mmwr/preview/ mmwrhtml/00021562.htm]

21. Kirkcaldy RD, Kidd S, Weinstock HS, Papp JR, Bolan GA: Trends in antimicrobial resistance in Neisseria gonorrhoeae in the USA: the Gonococcal Isolate Surveillance Project (GISP), January 2006-June 2012. Sex Transm Infect 2013, 89:5-10. doi:10.1136/sextrans-2012-050472.

22. Dillon JA, Trecker MA, Thakur SD: Gonococcal Antimicrobial Surveillance Program Network in Latin America and Caribbean 1990-2011: two decades of the gonococcal antimicrobial surveillance program in South America and the Caribbean: challenges and opportunities. Sex Transm Infect 2013, 89:36-41. doi:10.1136/sextrans-2012-050905.

23. Bala M, Kakran M, Singh V, Sood S, Ramesh V: Monitoring antimicrobial resistance in Neisseria gonorrhoeae in selected countries of the WHO South-East Asia Region between 2009 and 2012: a retrospective analysis. Sex Transm Infect 2013, 89:28-35. doi:10.1136/sextrans-2012-050904.

24. Hançali A, Ndowa F, Bellaji B, Bennani A, Kettani A, Charof R, El Aouad R: Antimicrobial resistance monitoring in Neisseria gonorrhoeae and strategic use of funds from the Global Fund to set up a systematic 
Moroccan gonococcal antimicrobial surveillance programme. Sex Transm Infect 2013, 89:24-27. doi:10.1136/sextrans-2013-051166.

25. Workowsky KA, Berman S, Centers for Disease Control and Prevention (CDC): Sexually transmitted diseases treatment guidelines 2010. MMWR Recomm Rep 2010, 59:1-116.

26. Bignell C, Unemo M, European STI, Board GE: European guideline on the diagnosis and treatment of gonorrhoea in adults. Int J STD AIDS 2012, 2013(24):85-92.

27. Tapsall J: Antimicrobial Resistance in Neisseria gonorrhoeae. Geneva, Switzerland: World Health Organization; 2001:1-58.

doi:10.1186/1471-2334-14-433

Cite this article as: Brunner et al:: Incidence and antimicrobial susceptibility of Neisseria gonorrhoeae isolates from patients attending the national Neisseria gonorrhoeae reference laboratory of Hungary. BMC Infectious Diseases 2014 14:433.

\section{Submit your next manuscript to BioMed Central and take full advantage of:}

- Convenient online submission

- Thorough peer review

- No space constraints or color figure charges

- Immediate publication on acceptance

- Inclusion in PubMed, CAS, Scopus and Google Scholar

- Research which is freely available for redistribution 